\title{
Study of maxillofacial fractures in patients referred to Ayatollah - Mousavi Hospital in Zanjan (2013-15)
}

\author{
I. Shirinbak ${ }^{1}$, B. Nazemi Salman ${ }^{2}, \underline{\text { S. Basir Shabestari }}{ }^{3}$, P. safavi ${ }^{4}$
}

\author{
${ }^{1}$ Department of Oral and Maxillofacial Surgery, School of Dentistry, Alborz University of Medical Science, Karaj, Iran \\ ${ }^{2}$ Department of Pediatric Dentistry, School of Dentistry, Zanjan University of Medical Sciences, Zanjan, Iran \\ ${ }^{3}$ Department of Oral Medicine, School of Dentistry, Alborz University of Medical Sciences, Karaj, Iran \\ ${ }^{4}$ Dentist, Zanjan, Iran \\ Corresponding Address: Samira Basir Shabestari, Alborz University of Medical Sciences, Karaj, Iran \\ Tel: +98-912-4469638, Email: samira_bsh2@yahoo.com \\ Received: 31 Jul 2017; Accepted: 29 Nov 2017
}

\section{* Abstract}

Background: After cerebrovascular and coronary diseases, trauma due to road accident is the leading cause of death in our country. Maxillofacial fractures have economic and psychological consequences in addition to effects on the aesthetic and function of a person. Because of high frequency of car accidents in Zanjan province roadways, evaluation of maxillofacial fractures is important.

Objective: The aim of study was to evaluate the epidemiologic characteristics of maxillofacial fractures in patients referred to Ayatollah - Mousavi Hospital in Zanjan in 2013-15.

Methods: In this descriptive retrospective study, personal's profile (age, sex), and fracture pattern (etiology and location) of 303 patients were selected by archive review and recorded in the informative form. Data were analyzed with descriptive statistics.

Findings: From 277 evaluated maxillofacial fractures patients who met the inclusion criteria in this study such as completeness and legibility of registered data, 229 patients (82\%) were male and 48 patients (18\%) female. The peak incidence of maxillofacial injury was observed in the age group of 21-31 years. Most and least frequent site for fracture were mandible (26.7\%) and condyle (6.9\%) respectively. The most common cause for maxillofacial fracture in sequence were: car accident (79.4\%), falling (8.3\%), violence and assaults (5.8\%).

Conclusion: The most common cause for maxillofacial fracture was car accident especially in young adult males. So, emergency relief for victims, vehicle safety, and increase public awareness about seat belt usage is suggested.

Keywords: Injuries, Maxillofacial fractures, Epidemiology

Citation: Shirinbak I, Nazemi Salman B, Basir Shabestari S, Safavi P. Study of maxillofacial fractures in patients referred to Ayatollah - Mousavi Hospital in Zanjan (2013-15). J Qazvin Univ Med Sci 2018; 21 (6): 38-45. 


\title{
بررسى شكستكى هاى فك و صورت در مراجعين به بيمارستان آيتالله موسوى زنجان

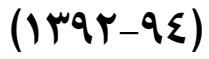

\author{
دكتر ايمان شيرين بك'، دكتر بهاره ناظمى سلمان'، دكتر سميرا بصيرشبسترى'، دكتر يدرام صفوىع
}

\author{
أرموه جراحى فك و صورت دانشكده دندانيز شكى دانشكاه علوم يزشكى البرز، كرج، ايران

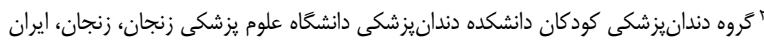

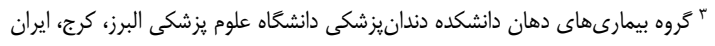

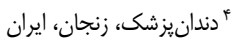

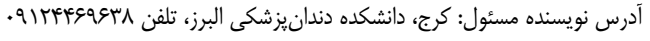 \\ تاريخ دريافت: 9 9/ه/9 ؛ تاريخ يذيرش: كرج
}

زمينه: در كشور ما بيشترين علت مرى و مير بعد از بيمارىهاى قلبى - عروقى، تروماى ناشى از تصادفات جادهاى است. شكستخى هاى ناحيه فـى

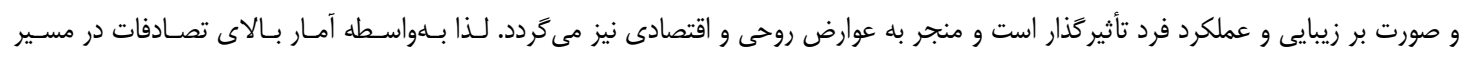

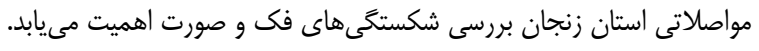

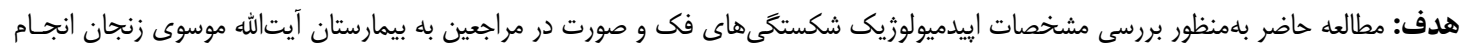

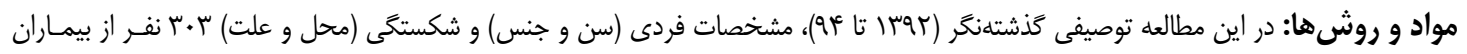

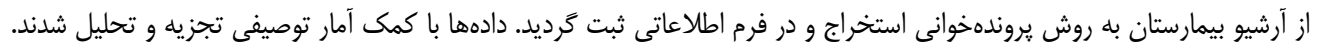

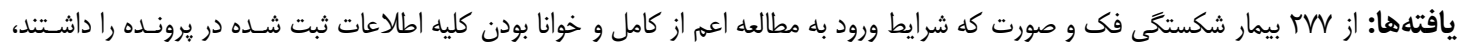

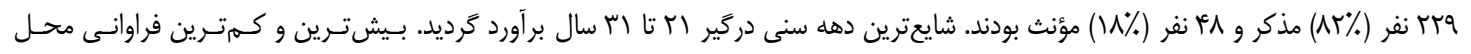

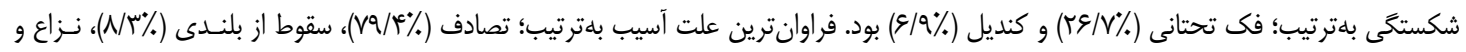

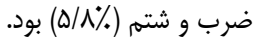

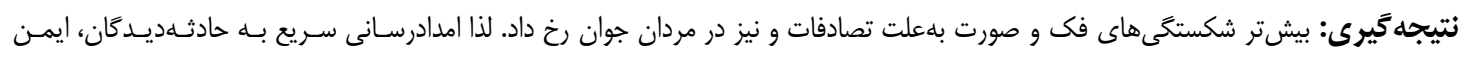

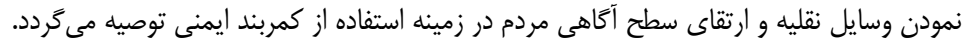
كليدوازهها: صدمات، شكستخى فى و صورت، اييدميولوزى

مقدمه:

صورت بخش عمدهاى از تروماها را تشكيل مىدهنـد كـه

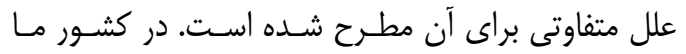

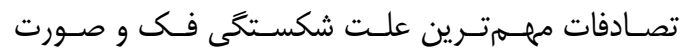
محسوب مىشود درحالى كه در كشـورهاى توسـعه يافتــه

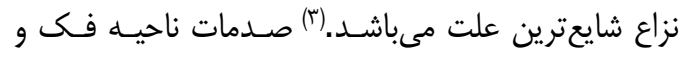

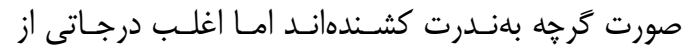

وازه تروما در ترمينولوزى جراحى به معناى وارد آمدن يكى نيروى فيزيكى است كـه ايجـاد صــدمه مـى كنـد. (ا)

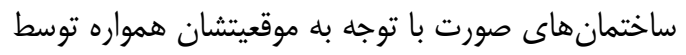

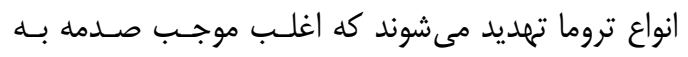

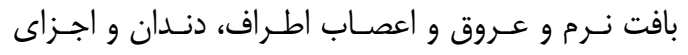

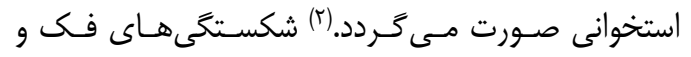


بررسى كليشههاى سىتىاسكن اورخانسهــــ شهميد

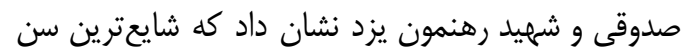

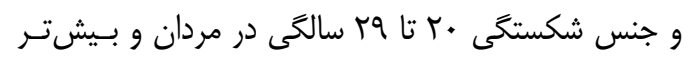

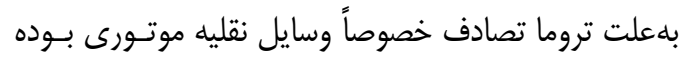

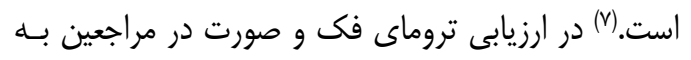

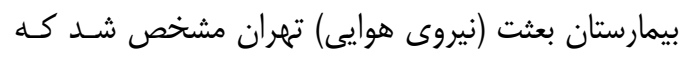

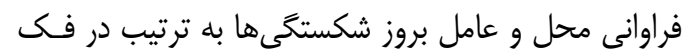

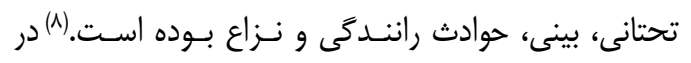

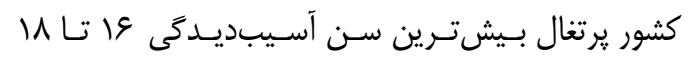

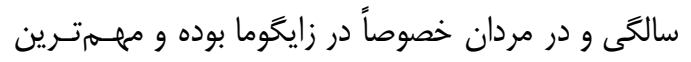

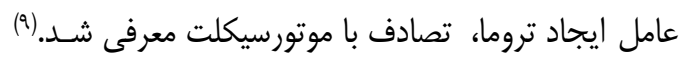

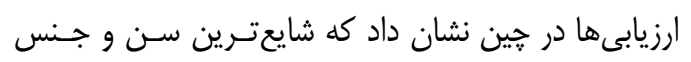
شكستخى فك و صورت در آ تا •r سالكى و در مـردان

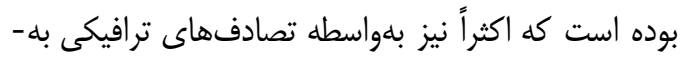

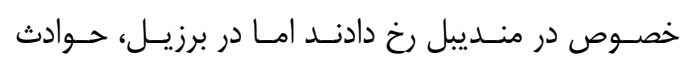

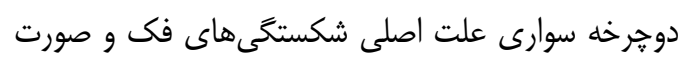

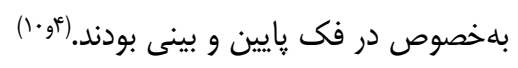

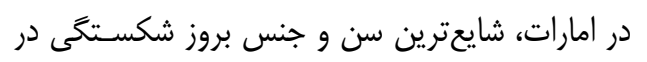

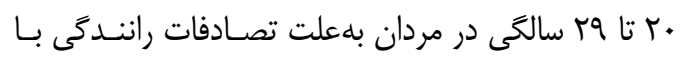

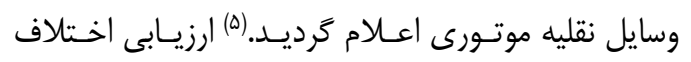

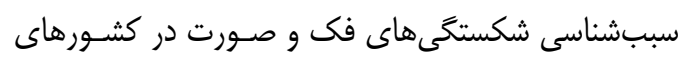

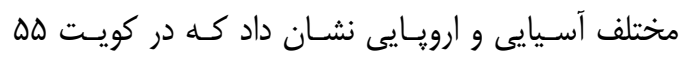

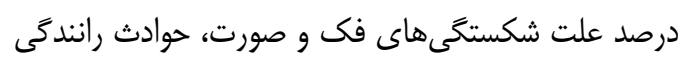

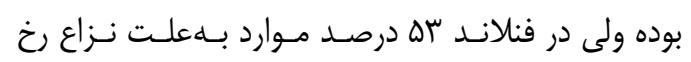

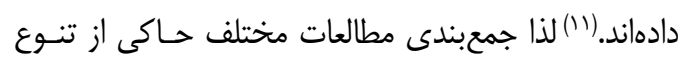

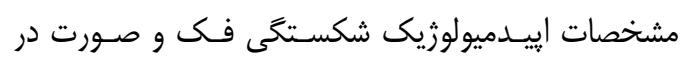

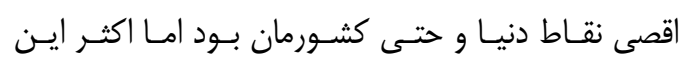
يزوهشها بر شيوع بيشتر شكستخى هاى فك و و صـورت در ناحيه منديبل مردان بلهعلت تصادف، تأكيد داشتند. علىرغم اهميت موضوع و نيز آمار بالاى تصادفات در

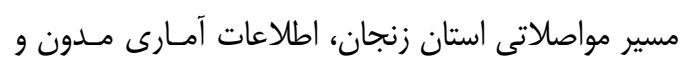

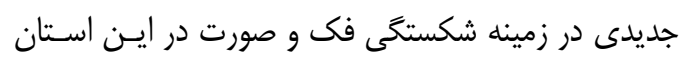

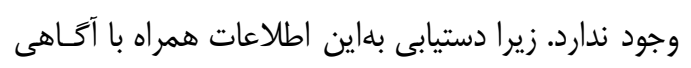
از ساختار فرهنگى و اجتماعى منطقه در ييشبينى و تأمين
بدشكلى و اختلال عملكرد را ايجاد مىنمايند كه اين امـر

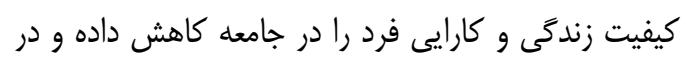

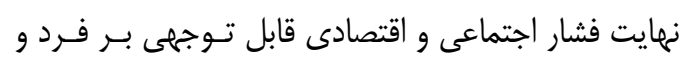

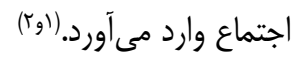

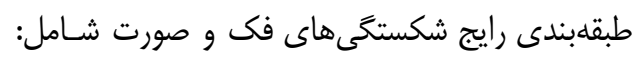
شكستخى هاى فك يايين (منديبل)، شكستخى هاى كاسـهـ

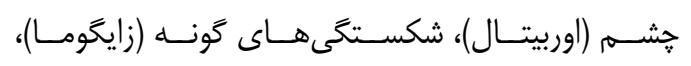

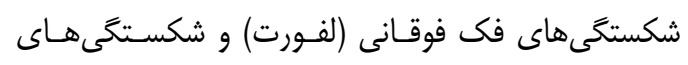

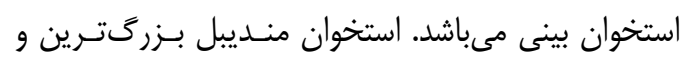

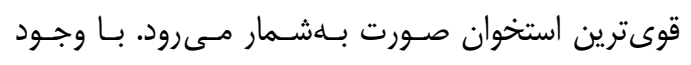
اختلافات زيادى كه در ميزان فراوانى علل شكستخى هاى

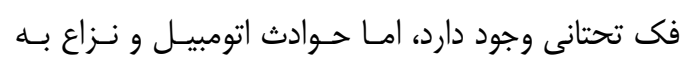

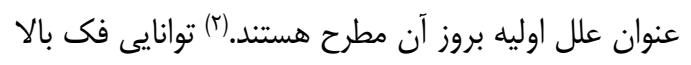

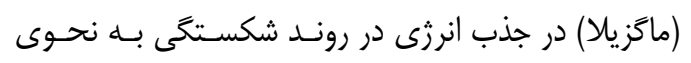

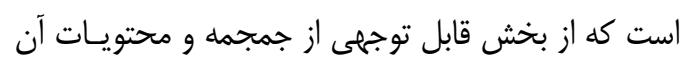

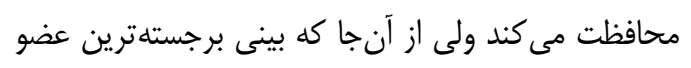
صورت است، شكستخى بينى شايعترين شكستخى سـر و و و كردن است. (") مورت شيوع شكستخىها در كشورهاى ييشـرفته و در حـال

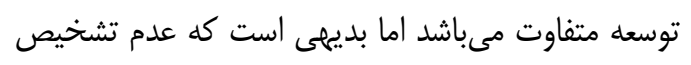

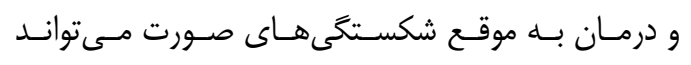

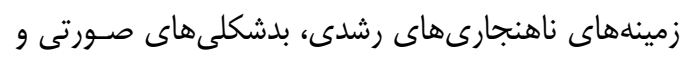

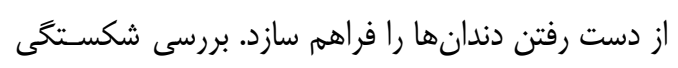

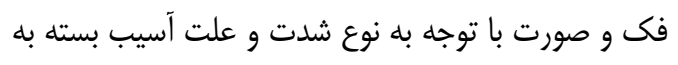

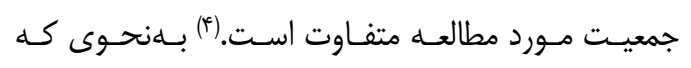
تصادفات در كثور نيجريه، ليبى، ارويا و آمريكا بـــعنـوان

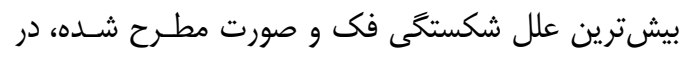

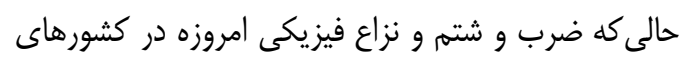

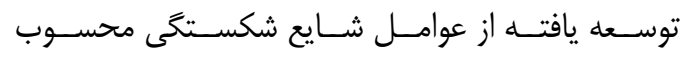

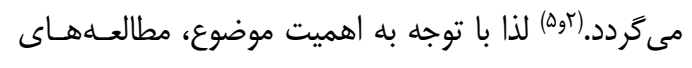

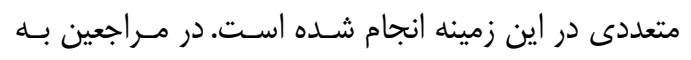

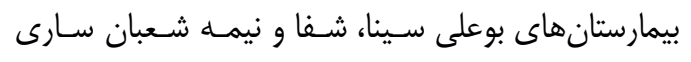

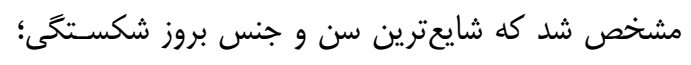

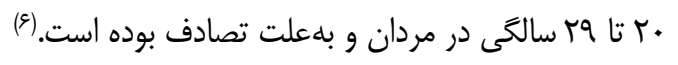


اخلاق مصـوب، ملاحظــات اخلاقـى در ايـن ی-رَوهش رعايت شده است.

\section{喧}

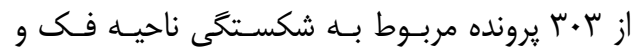

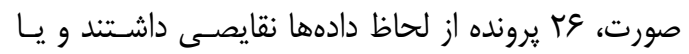
ناخوانا بودند، لذا از مطالعه حاضر حذف شدند. در نهايت از

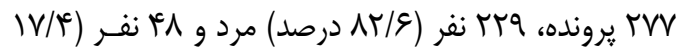
درصد) زن بودند. بدين ترتيب نسبت مرد به زن حسدود أ:

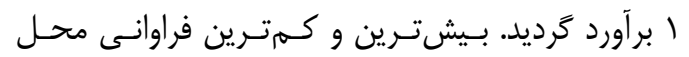
شكستخى بلهترتيب مربوط به فى تحتانى (V/V (

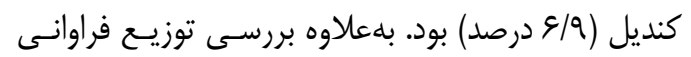

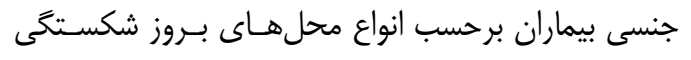

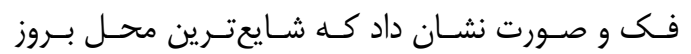
شكستخى در بين مردان و زنان، فى تحتانى اسـت البتـه اين نوع شكستخى در زنان شايعتر بود (جدول شماره ()).

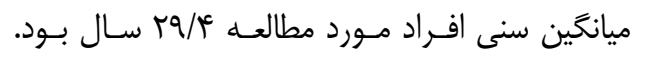
بيماران مورد بررسى از لحاظ سنى به هفت گـروه تقسـيم

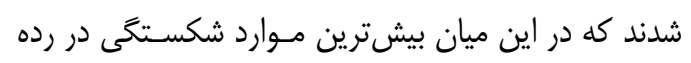
سنى آ تا اس سال (ז/هّ درصد) مشاهده گرديد (جدول

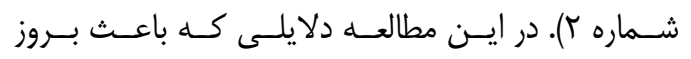
شكستخى هاى فك و صورت (بدون در نظر گرفتن جـنس يا سن مراجعين) شده بودند نيز بررسى و مشخص شد كد كه

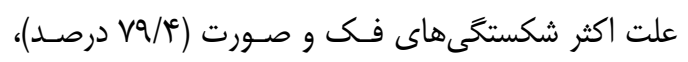

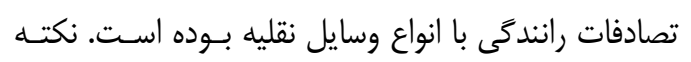

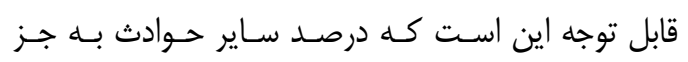
تصادفات شامل؛ نزاع، سقوط از بلندى و اصـابت اشـيا بـهـ

صورت در زنان بيشتر از مردان بود (جدول شماره س).
امكانات و آمادگى در مواجهه بـا ايـن صـدمات در مراكـز درمانى از اهميت قابل توجهى برخوردار است. لـذا در ايسن مطالعه، مشخصات إيبدميولوزيك شكستخى هـاى فـى و و صورت در مراجعين به بيمارستان آيتالله موسوى زنجــان مورد بررسى قرار گرفتند.

\section{شواد و روش ما:}

در اين مطالعه توصيفى خذشتهنگر بهصـورت مقطعى روسى اطلاعات دموگرافيك (سن و جنس) و دادههاى مربوط به به به شكستخى فى و صورت (اعـم از علـت و محـل) از ب. يرونده يزشكى بيمارانى كه طى سالهـاى بوسا الى

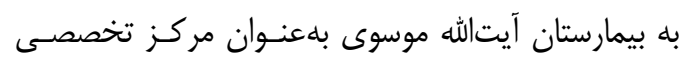

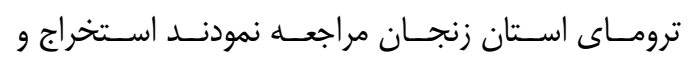

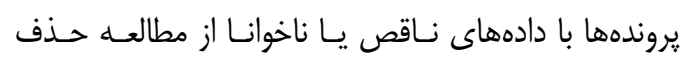

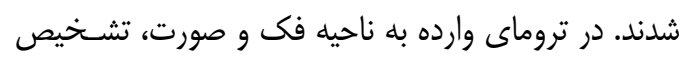

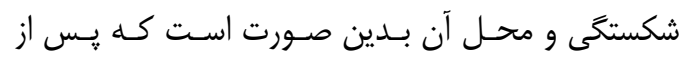
دريافت تاريخجه و معاينه بالينى دقيق به ارزيابى علايهم و

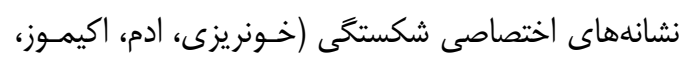

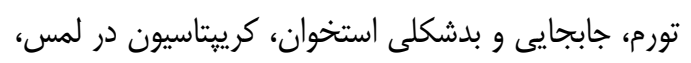

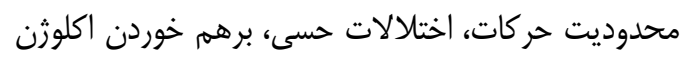

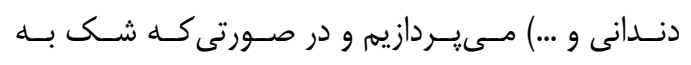
شكستخى وجود داشته باشد جهـت قطعيـت تشـخيص از

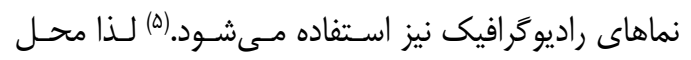
شكستخى بلهواسطه معاينه بالينى و لمس و بررسى اكلوزن

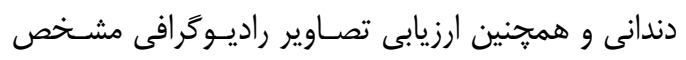
مىشود. (זوب) ابزار جمع آورى دادهها در اين تحقيق همٍجــون سـاير مطالعات مشابه شامل يروندهخوانى و جمع آورى اطلاعـات ثبت شده در يرونده يزشكى بيماران بود.(و..1-1) دادههـايى

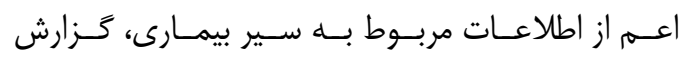

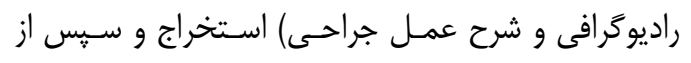

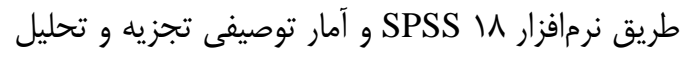

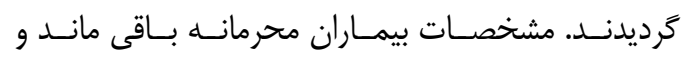

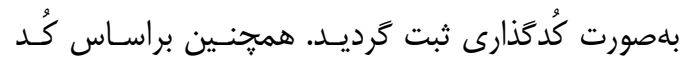


جدول ا - توزيع فراوانى محل شكستكى فك و صورت برحسب جنسيت

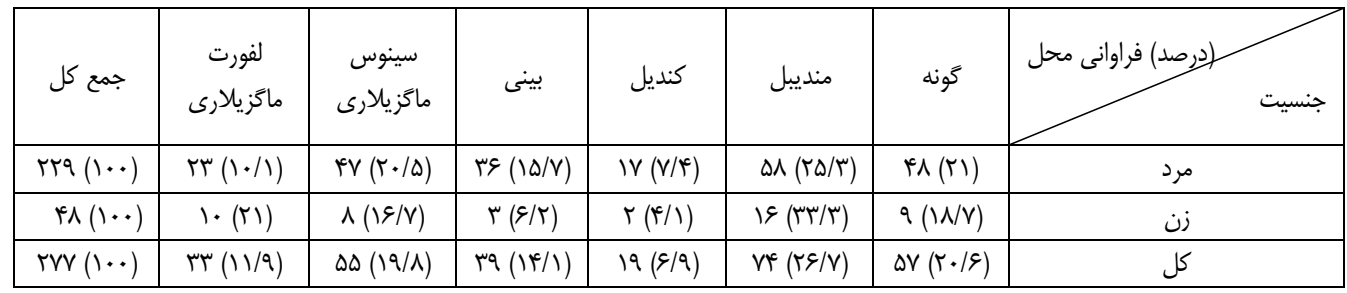

جدول ץ- توزيع فراوانى علت شكستكى برحسب تروه سنى

\begin{tabular}{|c|c|c|c|c|c|}
\hline جمع كل & اصابت اشيا به صورت & سقوط از بلندى & نزاع و ضرب و شتم & تصادف & كروه سنى (سال) \\
\hline$\pi(\kappa / r)$ & $\cdot$ & . & . & $\operatorname{Ir}(r g / V)$ & 1. \\
\hline$r(11 / 9)$ & . & . & $T(\Gamma / \Gamma)$ & $r \tau(V / \Lambda)$ & $r \cdot r$ (I) \\
\hline$Q \Lambda\left(\Gamma \Delta / \Gamma^{*}\right)$ & $\Delta(\mu / \mu \cdot)$ & $\Lambda(D / F \varphi)$ & $V(\mathcal{E} / V \mathcal{G})$ & $V \wedge(\Delta \% / \cdot 9)$ & $r \cdot|r|$ \\
\hline$p q(\mathrm{IV} / \mathrm{V})$ & $\Gamma(\Gamma / \cdot \Gamma)$ & $q(\% / \cdot 1)$ & $F(T / V Y)$ & 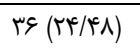 & (F) \\
\hline (IT) & $r(\Gamma / I V)$ & $r(\tilde{F} / \mathrm{Vq})$ & $r(\mathcal{F} / \mathrm{Vq})$ & $r \Lambda(\varphi \varphi / \varphi \varphi)$ & D. \\
\hline$r V(q / v)$ & $r(r / V V)$ & $r(r / V V)$ & $1(1 / \Delta \Lambda)$ & $M(M r / Q T)$ & S4اها \\
\hline$r r(V / q)$ & $G(T V / \Psi)$ & $F(1 N / T)$ & . & $I T(\Delta F / \Delta)$ & D \\
\hline
\end{tabular}

جدول س- توزيع فراوانى علت شكستكى برحسب جنسيت

\begin{tabular}{|c|c|c|c|c|c|}
\hline جمع كل & اصابت اشيا به صورت & سقوط از بلندى & نزاع و ضرب و شتم & تصادف & حنسيت \\
\hline rrq $(1 .)$. & $1 f(\xi / 1)$ & $I V(V / F)$ & $\pi(\Delta / v)$ & $\operatorname{I\wedge D}(\Lambda \cdot / \Lambda)$ & مرد \\
\hline$\psi \wedge(1 \cdots)$ & $F(\Lambda / r)$ & $9(1 T / \Delta)$ & $r(\xi / r)$ & $r \Delta\left(V^{\top}\right)$ & زن \\
\hline $\operatorname{rrv}(1 \cdot)$. & $\|(\xi / \Delta)$ & $r(N / r)$ & $19(\Delta / \Lambda)$ & $\pi \cdot(\mathrm{V} / \mathrm{F})$ & كل \\
\hline
\end{tabular}

يافته با نتايج مطالعات انصـارى در همــان، فـرى ئـرا در

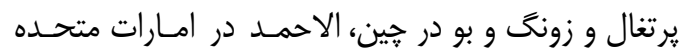

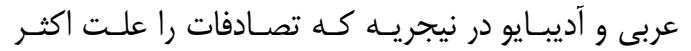

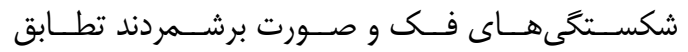

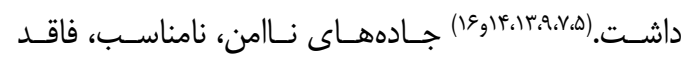

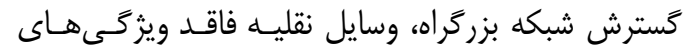

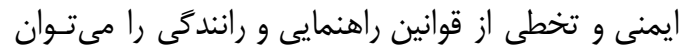

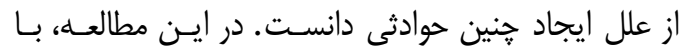

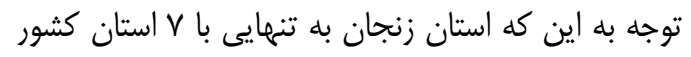

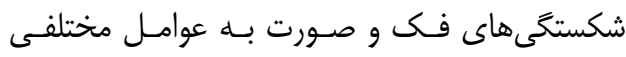

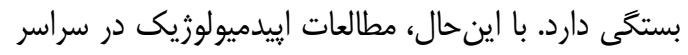

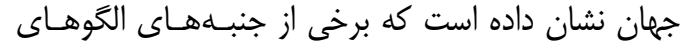

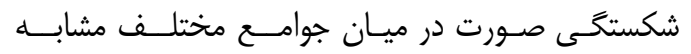

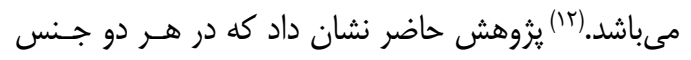

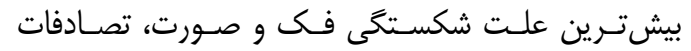

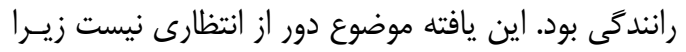

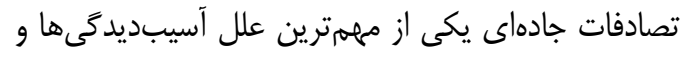

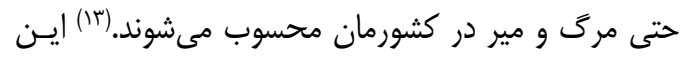


مى شود، باشد. از طرفى ديخر جون در اين مطالعـه درصـــ

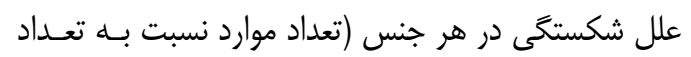

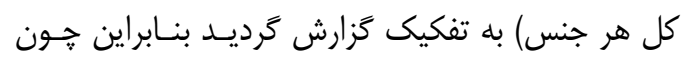

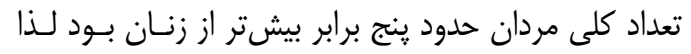

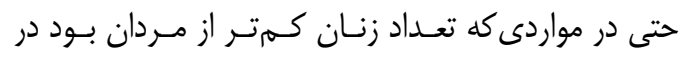

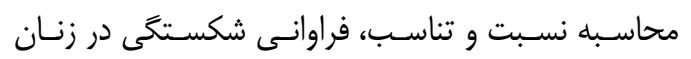

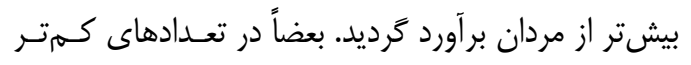

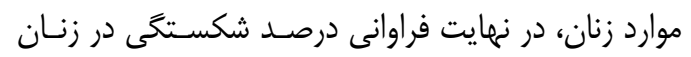

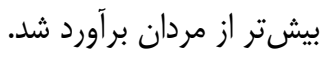

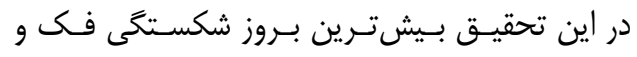

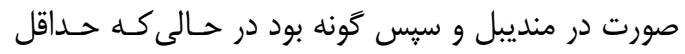

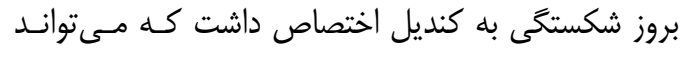

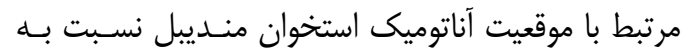

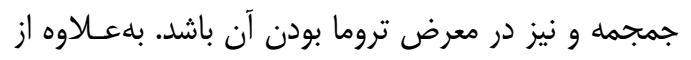

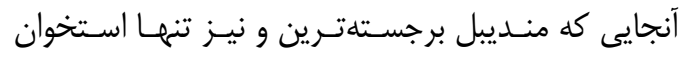

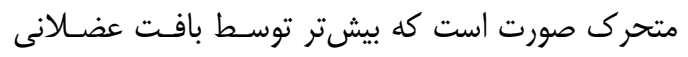
حمايت مىشود لذا شانس بيشترى براى شكستـتى دارد

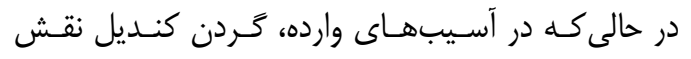

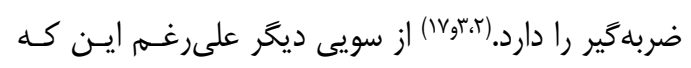

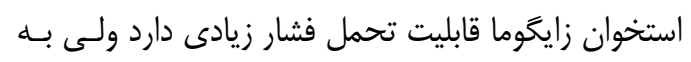
جهت موقعيت آن كه در قسمت لترالى صورت مى فياشد لذا

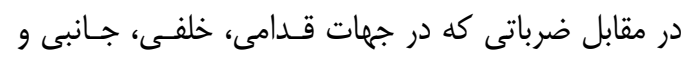

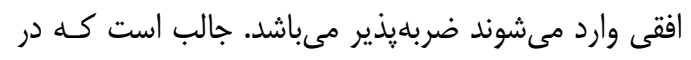

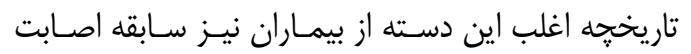

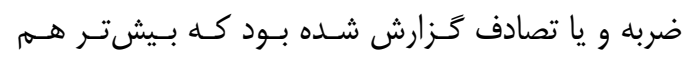
بلهورت اكيموز و تورم دور جشم تظاهر يافتند.

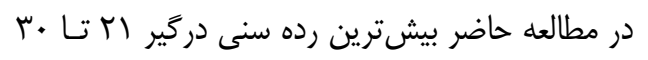

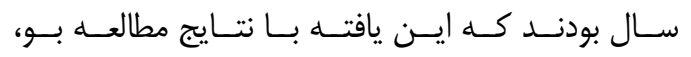

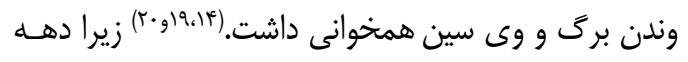

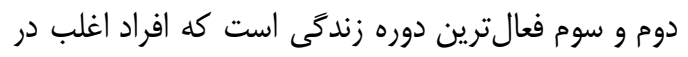

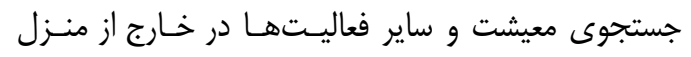
حضور دارند لذا بيشتر در معرض شرايط يُرخطر از جملـه فئه

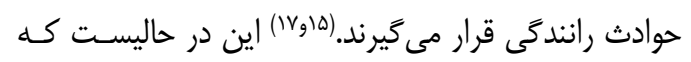

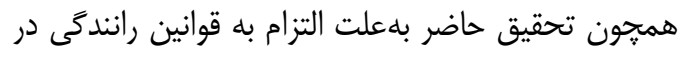

(اردبيل، كَيلان، قـزوين، همـدان، كردسـتان، آذربايجـان

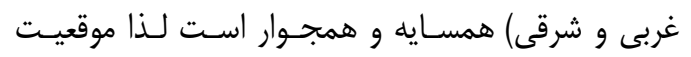

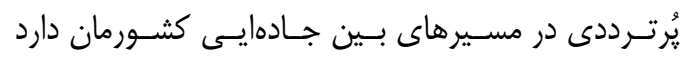

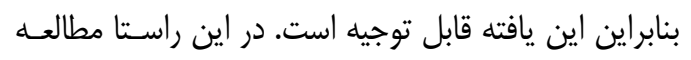

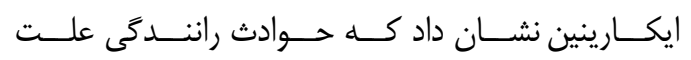
شكستكى هاى فى و صورت در Dه، V و سب درصد موارد

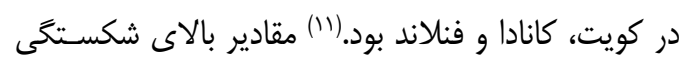
فك و صورت ناشى از تصادفات در كشور كويت همسو با فالنا بودي

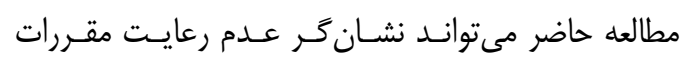
رانندگى و يا التزام به آنها در كشورهاى شرقدى نشان باشد.

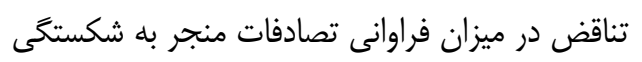

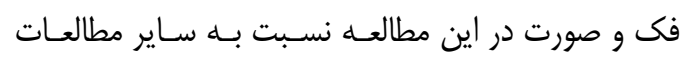

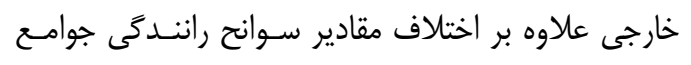

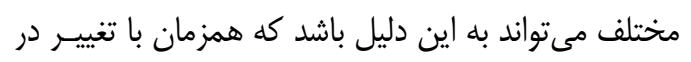

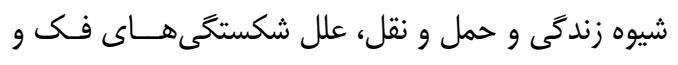

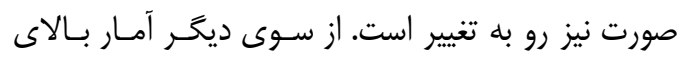

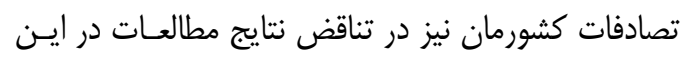

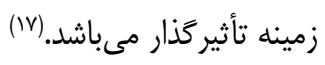
براساس نتايج مطالعه حاضر فراوانى شكسـتخى هــاى

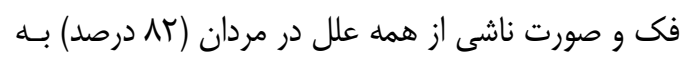

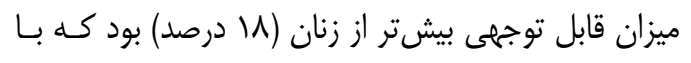

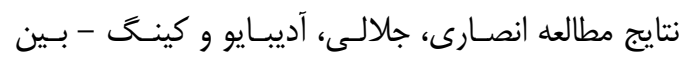

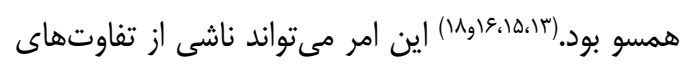

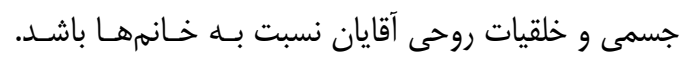

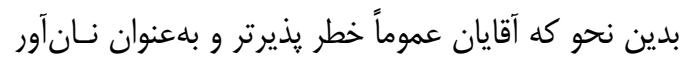

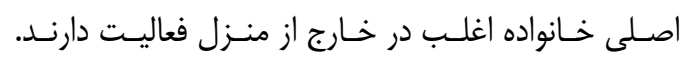

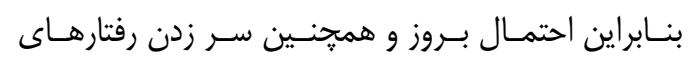

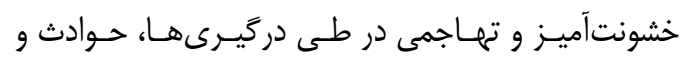

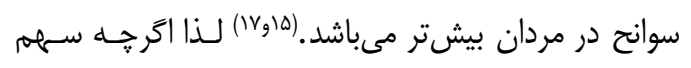

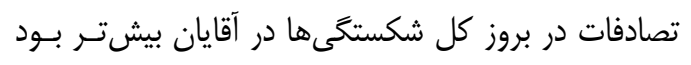

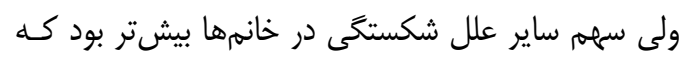

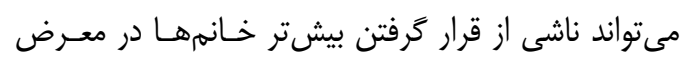

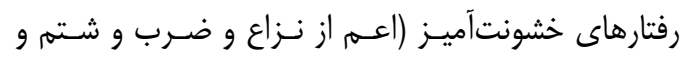
اصابت اشيا بلهورت) كه اغلـب از سـوى آقايـان اعمـال 
1122.1000132 doi: $10.4172 / 2161-1122$. 1000132.

2. James R, Hupp JD, Myron R, Tucker M, Edward E. Contemporary oral and maxillofacial surgery. 6th ed. Elsevier: StLouis Missouri; 2014. Part VI. Chapter 25.

3. Mello Filho FV, Ricz H. Epidemiological modifications of facial trauma and its implications. Braz J Otorhinolaryngol 2014; 80(3): 187-8. doi: 10.1016/j.bjorl.2014.05. 006.

4. Charcanovic BR, Abreu MH, Freire-Maia B, Souza LN. Facial fractures in children and adolescents: a retrospective study of 3 years in a hospital in Belo Horizonte, Brazil. Dent Traumatol 2010; 26(3): 262-70. doi: 10. 1111/j.1600-9657.2010.00887.x.

5. Al Ahmad HE, Jaber MA, Abu Fanas SH, Karas M. The pattern of maxillofacial fractures in sharjah, United Arab Emirates: a review of 230 cases. Oral Surg Oral Med Oral Phthol Oral Radiol Endod 2004; 98(3): 16670. doi:10.1016/j.tripleo.2004.01.020.

6. Nosrati K, Babaei S, Ashrafi Moshkabadi J. A survey of mandibular fracture regions of patients of Boualisina, Shafa, Nime shaban hospital in Sari from 2005 until 2006. J Ghasr-e-Baran 2009; 1(1): 37-41. [In Persian] 7. Ezoddini Ardakani F, Nafisi Moghadam R, Chavoshian M, Hashemian Z. Relative frequency of maxillofacial fracture in CTscan radiographs in Shahid Sadoghi and Shahid Rahnemoun emergency departments in Yazd from 2007 till 2010. J Shahid Sadoughi Univ Med Sci 2012; 19(6): 821-30. [In Persian]

8. Babaei AR. The study of maxillofacial trauma cases referred to besaat Hospital. Ann Mil Health Sci Res 2003; 1(3): 185-8. [In Persian].

9. Ferreira P, Marques M, Pinho C, Rodrigues

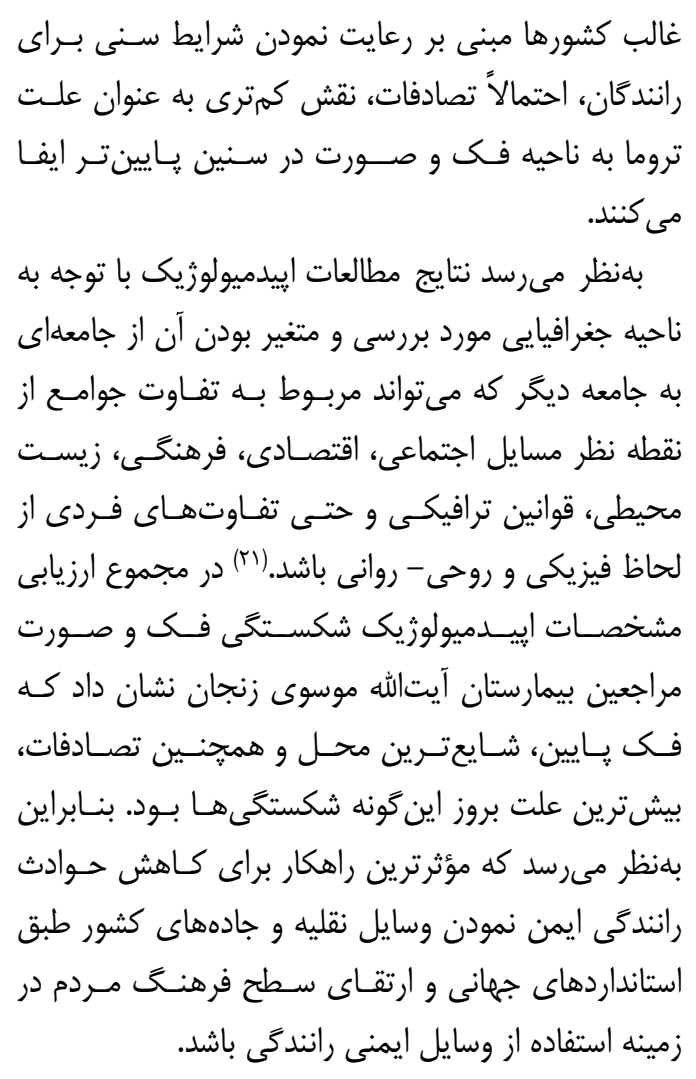

كلياس

بدينوسيله از معاونت يزوهشى دانشعاه علوم يزشكى

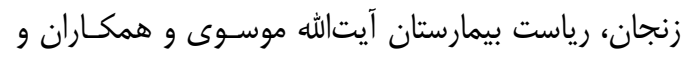

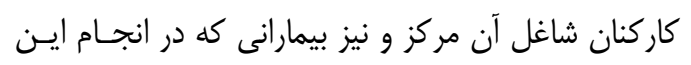

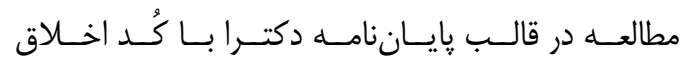

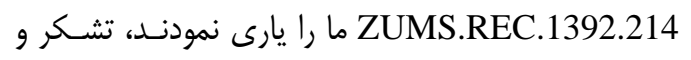
قدردانى مىنماييم.

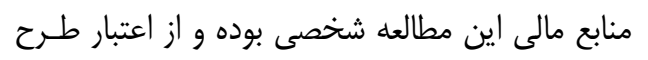
يزوهشى استفاده نشده است.

\section{مراجع:}

1. Ogundipe OK, Afolabi AO, Adebayo O. Maxillofacial fractures in Owo, South Western Nigeria: a 4 year retrospective review of pattern and treatment outcome. J Dentistry 2012; 2: 132. doi: 10.4172/2161- 
16. Adebayo ET, Ajike OS, Adekeye EO. Analysis of the pattern of maxillofacial fractures in Kaduna, Nigeria. $\mathrm{Br} \mathrm{J}$ Oral Maxillofac Surg 2003; 41(6): 396-400. doi: 10.1016/S0266-4356(03)00165-7.

17. Blyer SM. Facial trauma in maxillofacial surgery. In: Fonseca EJ. Oral and maxillofacial surgery. 4th ed. Philadelphia: W.B Saunders; 2017. 678-96. (Vol 3)

18. Qing-Bin Z, Zhao-Qiang Z, Dan C, Yan Z. Epidemiology of maxillofacial injury in children under 15 years of age in southern China. Oral Surg Oral Med Oral Pathol Oral Radiol 2013; 115(4): 436-41. doi: 10.1016/ j.000o.2012.04.026.

19. van den Bergh B, Karagozoglu KH, Heymans MW, Forouzanfar T. Aetiology and incidence of maxillofacial trauma in Amsterdam: a retrospective analysis of 579 patients. J Craniomaxillofac Surg 2012; 40(6): 165-9. doi: 10.1016/j.jcms.2011.08. 006.

20. Weihsin H, Thadani S, Agrawal M , Tailor S, Sood R, Langalia A, et al. Causes and incidence of maxillofacial injuries in India: 12- year retrospective study of 4437 patients in a tertiary hospital in Gujarat. $\mathrm{Br} \mathrm{J}$ Oral Maxillofac Surg 2014; 52(8): 693-6. doi: 10.1016/j.bjoms.2014.07.003.

21. Mesgarzadeh AH, Shahamfar M, Azar SF, Shahamfar J. Analysis of the pattern of maxillofacial fractures in north western of Iran: a retrospective study. J Emerg Trauma shock 2011; 4(1): 48-52. doi: 10.4103/09742700.76837 .
J, Reis J, Amarante J. Midfacial fractures in children and adolescents: a review of 492 cases. Br J Oral Maxillofac Surg 2004; 42(6): 501-5. doi: 10.1016/j.bjoms.2004.06.006.

10. Zhong G, Chao G, Jie L. Retrospective study of 645 cases with maxillofacial fractures. Progress in Modern Biomedicine 2009; 9: 737-45.

11. Oikarinen K, Schutz P, Thalib L, Sandor GK, Clokie C, Meisami T, et al. Differences in the etiology of mandibular fractures in Kuwait, Canada, and Finland. Dent Traumatol 2004; 20(5): 241-5. doi: 10.1111/ j.1600-9657.2004.00243.x.

12. Hogg NJ, Stewart TC, Armstrong JE, Girotti MJ. Epidemiology of maxillofacial injuries at trauma hospitals in Ontario, Canada, between 1992 and 1997. J Trauma 2000; 49(3): 425-32.

13. Ansari $\mathrm{MH}$. Maxillofacial fractures in Hamedan province, Iran: a retrospective study (1987-2001). J Craniomaxillofac Surg 2004; 32(1): 28-34. doi: 10.1016/j.jcms.2003.07. 010.

14. Bo B, Gu X, Zhou S. An epidemiologic retrospective study of 1693 maxillofacial injuries. Hua Xi Kou Qiang Yi Xue Za Zhi 1998; 16(1): 56-8.

15. Jalali S, Nosrati K, Sarrafan N, Bijani A, Moodi E. Prevalence of maxillofacial fractures in patients referring to Babul Shahid Beheshti hospital during 2011 to 2013. J Urmia Uni Med Sci 2015; 25(12): 1112-8. 